\title{
'Dexamethasone-mannitol-hyperbaric oxygen' combination therapy is effective for patients with delayed neurological sequelae after acute carbon monoxide poisoning
}

\author{
Dazhi Guo $m D$, Ruijun Xue $m D$, Ya'nan Qi $m D$, Yan Lv $m D$, Xiangen Meng $m D$, Shuyi \\ Pan $M D$
}

Department of Hyperbaric Oxygen, $6^{\text {th }}$ Medical Center of PLA General Hospital, Beijing, China

\begin{abstract}
Background: Delayed neurological sequelae after carbon monoxide poisoning (DNS) is the most common neuropsychiatric sequelae of acute carbon monoxide $(\mathrm{CO})$ poisoning. At present, there is no effective method to prevent or treat DNS. This study was performed to evaluate the efficacy of the combined application of dexamethasone, mannitol and hyperbaric oxygen (HBO2) in the treatment of patients with DNS. Methods: A total of 312 patients with DNS were recruited and randomly assigned into the experimental group (10 mg/day dexamethasone, $100 \mathrm{ml} / 12 \mathrm{~h}$ mannitol + $\mathrm{HBO} 2$ therapy) and the control group (HBO2 only). All patients received conventional treatment. We used the Mini-Mental State Examination (MMSE) scale to assess the cognitive function, the remission rate (RR) to assess the clinical efficacy and the National Institutes of Health Stroke Scale (NIHSS) to assess the neurological function. In addition, we measured myelin basic protein (MBP) levels in the cerebrospinal fluid (CSF) to assess the extent of nerve damage. Results: Compared with the control group, the experimental group had significantly increased average MMSE score $(\mathrm{P}=0.035)$ and $\mathrm{RR}(\mathrm{P}=0.021)$, significantly reduced average NIHSS score $(\mathrm{P}=0.028)$ and significantly lower MBP level in CSF $(\mathrm{P}=0.0019)$ after 4 weeks of treatment. Furthermore, compared with patients who received dexamethasone alone, patients who received dexamethasone and mannitol had higher average MMSE score $(\mathrm{P}=0.012)$ and RR $(P=0.038)$ and lower average NIHSS score $(P=0.022)$ and MBP level in CSF $(P=0.002)$. Dexamethasone and mannitol combined with $\mathrm{HBO} 2$ did not significantly increase adverse effects. Conclusion: The combination therapy of dexamethasone-mannitol-HBO2 is better in treating DNS than $\mathrm{HBO} 2$ alone and $\mathrm{HBO} 2$ combination with dexamethasone, and it can be used as a potential new therapy in the future.
\end{abstract}

Keywords: Hyperbaric oxygen, delayed neurological sequelae after carbon monoxide poisoning, dexamethasone, mannitol, myelin basic protein

\section{INTRODUCTION}

Carbon monoxide $(\mathrm{CO})$ poisoning is one of the most common causes of death from poisoning. Accidental $\mathrm{CO}$ poisoning occurs in approximately 15,000 people worldwide each year, accounting for approximately two-thirds of reported deaths..$^{1,2}$ Approximately one-third of patients with coma who survive acute $\mathrm{CO}$ poisoning will develop delayed neurological sequelae after carbon monoxide poisoning (DNS; also called delayed encephalopathy). DNS refers to the recurrence of neuropsychiatric symptoms after an interval of apparent normality (also called 'lucid interval',
2-60 days, with mean duration of 22 days) following apparent recovery from acute poisoning symptoms (disorder of consciousness). The characteristic neuropsychiatric symptoms of DNS include psychiatric symptoms, short-term memory impairment, gait disturbance, seizures, cortical blindness, hallucinations, unresponsiveness, low intelligence, dementia, increased muscle tone in the limbs, incontinence and coma. The clinical outcome varies widely from complete recovery to progressive deterioration until vegetative state or death, resulting in serious economic and social burden. ${ }^{3-5}$

Address correspondence to: Dazhi Guo, Department of Hyperbaric Oxygen, The Sixth Medical Center, PLA General Hospital. No. 6, Fucheng Rd, Haidian District, Beijing 100048, China. Tel.: +86-10-66957596; E-mail: guodazhigod1983@163.com

Date of Submission: 4 March 2021; Date of Acceptance: 24 May 2021

https://doi.org/10.54029/2021zsy 
The pathophysiological mechanisms of $\mathrm{CO}$ poisoning-induced brain damage remain unclear. Currently, DNS may be related to the tissue hypoxia induced by $\mathrm{CO}$ competition with haemoglobin ${ }^{6}$, mitochondrial oxidative stress $^{7}$, perivascular oxidative stress caused by intravascular neutrophil activation ${ }^{8}$, autoimmunological attack due to the alteration in myelin basic protein (MBP) ${ }^{9}$, excitatory amino acid toxicity ${ }^{10}$ and oligodendrocyte regeneration failure. ${ }^{11}$

To date, there is no effective way to prevent and treat DNS. Fortunately a lot of clinical neurorestorative strategies have been explored for restoring damaged nerves or sequel of neurological diseases and injuries recent years. ${ }^{12-14}$ These strategies may help to improve the chances for restoring functions or/and structures of DNS. Several studies have compared the effects of normobaric oxgen (NBO, 100\% oxygen at 1 atmosphere) and hyperbaric oxygen (HBO2, 100\% oxygen at 2.5-3 atmospheres) in the treatment of $\mathrm{CO}$ poisoning and found that both strategies can increase the dissociation rate of $\mathrm{CO}$ from haemoglobin by increasing the partial pressure of oxygen. However, the existing evidence cannot prove that the two strategies have different effects on the prognosis of patients with $\mathrm{CO}$ poisoning. ${ }^{15-22}$ Nevertheless, $\mathrm{HBO} 2$ can reverse the inflammatory response and mitochondrial dysfunction caused by $\mathrm{CO}$ poisoning and promote the recovery of damaged brain cells. Thus, experts in the field of hyperbaric medicine recommend $\mathrm{HBO} 2$ for the treatment of $\mathrm{CO}$ poisoning, especially patients with loss of consciousness, ischaemic heart damage, neurological deficits, severe metabolic acidosis and/or carboxyhaemoglobin $(\mathrm{COHb})$ greater than $25 \% .^{5}$ If conditions permit, the above patients should be treated with $\mathrm{HBO} 2$ immediately. In addition, some studies have used $\mathrm{HBO} 2$ combined with drugs to treat DNS. Xiang et al. have found that the combined application of dexamethasone and $\mathrm{HBO} 2$ therapy is better than $\mathrm{HBO} 2$ therapy as a monotherapy for patients with DNS. Compared with low doses of dexamethasone, high doses of dexamethasone has better results. ${ }^{23}$

The head computed tomography (CT) and magnetic resonance imaging (MRI) of patients with DNS often show bilateral symmetric fusion lesions in the white matter (WM) around the periventricular and semi-oval centres. ${ }^{24}$ Although diffusion-weighted imaging (DWI) is often used to show the presence, severity and extent of cytotoxic oedema in early (6 h) and early (24 h), DWI signal intensity in patients with DNS symptoms 2 weeks after $\mathrm{CO}$ poisoning continue to increase. ${ }^{25,26}$ These findings suggest that neuroinflammation and oedema caused by $\mathrm{CO}$ poisoning may play an important role in the pathophysiology of $\mathrm{CO}$ poisoning-induced brain injury and the development of DNS. Therefore, this study aimed to evaluate whether the combination of 'dexamethasone-mannitol-HBO2' can further reduce the incidence and severity of DNS. In addition, some studies have suggested that MBP may be a predictor of DNS. ${ }^{27}$ We also compared the MBP levels in the cerebrospinal fluid (CSF) of patients with DNS before and after treatment.

\section{METHODS}

The Medical Ethics Committee of the Sixth Medical Center of the General Hospital of the Chinese People's Liberation Army reviewed and approved the purpose and design of our work. This clinical trial was performed between May 2017 and December 2019. Patients that met the following criteria were included: 1) Patients with a clear history of $\mathrm{CO}$ poisoning; 2) Patients with a history of coma; 3) Patients who met the criteria of DNS; 4) Patients with Mini-Mental State Examination (MMSE) score of not more than 24; and 5) Patients or family member who provided written informed consent. The following were the exclusion criteria: 1) Patients who were allergic to dexamethasone; 2) Patients with poor blood glucose control; 3) Patients with renal insufficiency; 4) Patients with intellectual disability prior to the $\mathrm{CO}$ poisoning; 5) Pregnancy; 6) Patients older than 80 years; 7) Patients with bullae and pneumothorax; and 8) Patients with contraindications to $\mathrm{HBO} 2$. In total, 312 patients with DNS were included.

The included patients were randomly assigned into two groups in a 1:1 ratio: the experimental and control groups. We used the random number table to conduct randomisation, and the raters and patients were blinded to allocation. All patients received conventional treatments, including antibiotics and sputum suction to prevent lung infections, maintaining stable blood pressure and blood glucose, regulating water and electrolyte balance, nutritions and vitamins. The patients in the two groups were placed in the oxygen chamber with $0.16 \mathrm{MPa}$ absolute pressure for $100 \mathrm{~min} /$ day. The patients in the experimental group were further randomly assigned into two groups in a $1: 1$ ratio. Half of the patients received $10 \mathrm{mg} /$ day dexamethasone (E1 group). The other half received $10 \mathrm{mg} /$ day dexamethasone and $100 \mathrm{ml} / 12$ $\mathrm{h}$ mannitol intravenously (E2 group). The placebo 
in the control group was given dextrose sodium chloride solution. The dosage of dexamethasone and $\mathrm{HBO} 2$ was according to the previous study by Xiang et al. with slight modifications. ${ }^{23}$ The medication was given for 4 consecutive weeks.

\section{Hyperbaric oxygen therapy}

All the included patients in the control and experimental groups received $\mathrm{HBO}$ in a hyperbaric oxygen chamber (Hyperbaric Oxygen Chamber Factory, Ningbo, China) immediately after enrollment. The treatment consisted of $100 \%$ oxygen at $0.16 \mathrm{MPa}$ absolute pressure for 60 min (including $20 \mathrm{~min}$ each for compression and decompression) per treatment, once a day, 5 days per week, for 4 weeks.

\section{Outcome assessment}

The outcomes were assessed immediately after the 4-week period of treatment. The MMSE score was used to assess the cognitive function. Complete recovery (CR), partial recovery and no relief were defined according to the MMSE score. The remission rate (RR) was defined by the CR percentage. The National Institutes of Health Stroke Scale (NIHSS) was used to assess the neurological function. We also collected the CSF of patients before and after the treatment and estimated the MBP levels by enzyme-linked immunosorbent assay. The potential adverse events were recorded and analysed

\section{Statistical analysis}

We used SPSS 19.0 statistical software package for statistical processing. Continuous data were shown as mean + standard deviation $(\overline{\mathrm{X}}+\mathrm{s})$. Paired t-test was used for comparison before and after treatment, and the analysis of covariance (ANCOVA) was utilised to assess the effect of the treatment modalities on the post-treatment MMSE scores, NIHSS scores and MBP level. Enumeration data were shown as frequency and percentage. Comparisons between groups were performed using $\mathrm{x}^{2}$ test or Fisher exact probability method. The intention-to-treat analysis was conducted, and a P-value of 0.05 was considered to be significant.

\section{RESULTS}

In total, 312 patients with DNS were included in the study. The included patients with DNS were randomly assigned into two groups, each group had 156 patients. In the experimental group, 78 patients received $10 \mathrm{mg} /$ day dexamethasone and $100 \mathrm{ml} / 12 \mathrm{~h}$ mannitol, and the other 78 patients received $10 \mathrm{mg} /$ day dexamethasone. The average $\mathrm{CO}$ exposure time in the experimental and control groups was $(10.0 \pm 2.0) \mathrm{h}$ and $(9.55 \pm 1.2) \mathrm{h}$, respectively. The average 'lucid interval' was (15.6 $\pm 6.7)$ days and $(14.9 \pm 7.2)$ days. No significant differences were observed in other baseline data, such as age, body mass index and $\mathrm{COHb}$ levels between the experimental and control groups. The details of the two groups is given in Table 1 . No significant difference was observed in the baseline characteristics between patients who received dexamethasone + mannitol and patients who received dexamethasone alone.

Table 1: Demographic characteristics of the included patients

\begin{tabular}{lcccc}
\hline Variable & Control & Experimental & t/x2 & P-value \\
\hline Number & 156 & 156 & - & \\
Female/male & $61 / 95$ & $69 / 87$ & 0.041 & 0.872 \\
Age (years) & $52.7 \pm 10.6$ & $53.1 \pm 11.0$ & 0.431 & 0.612 \\
BMI $\left(\mathrm{kg} / \mathrm{mm}^{2}\right)$ & $23.7 \pm 2.6$ & $24.47 \pm 3.2$ & 0.511 & 0.474 \\
Education level & $10.1 \pm 4.2$ & $11.07 \pm 4.5$ & 0.112 & 0.810 \\
(years) & $39 / 117$ & $41 / 115$ & 1.677 & 0.210 \\
Work type (Me/Ma) & $9.55 \pm 1.2$ & $10.0 \pm 2.0$ & 0.681 & 0.556 \\
CO exposure time (h) & $22.7 \pm 9.8$ & $22.2 \pm 10.4$ & 0.437 & 0.527 \\
COHb levels (\%) & $15.6 \pm 6.7$ & $14.9 \pm 7.2$ & 0.572 & 0.387 \\
Latent phase & 32 & 35 & 0.910 & 0.343 \\
Hypertension & 27 & 30 & 0.706 & 0.420 \\
Diabetes & & & & \\
\hline
\end{tabular}




\section{MMSE score}

Before the treatment, the average scores of MMSE between the experimental group and the control group were similar (experimental group: $8.40 \pm$ 0.67 vs. control group: $8.36 \pm 0.59, \mathrm{P}=0.887$ ). After the treatment, the average MMSE scores of the experimental and control groups were significantly increased (experimental group: after $18.75 \pm 0.43$ vs. before treatment $8.40 \pm 0.67$, $\mathrm{P}=0.007$; control group: after $15.66 \pm 0.41$ vs. before treatment $8.36 \pm 0.59, \mathrm{P}=0.002$ ). The ANCOVA results showed that the MMSE score of the experimental group was significantly higher than that of the control group (experimental group: $18.75 \pm 0.43$ vs. control group: $15.66 \pm 0.41, \mathrm{P}$ $=0.035)$. Compared with patients who received dexamethasone alone, patients who received dexamethasone + mannitol had a significantly higher average MMSE score (E2 group: 18.69 \pm 0.51 vs. E1 group: $15.01 \pm 0.38, \mathrm{P}=0.012$ ) (Figures 1 and 2).

\section{The remission rate $(R R)$}

As shown in Table 2, the MMSE scores before treatment in both groups were $<24$ before treatment. After treatment, 72 patients in the experimental group and 38 patients in the control group had MMSE scores exceeding 24. These patients met the CR criteria. The RR of the experimental group was significantly higher than that of the control group (46.2\% vs. $24.4 \%, \mathrm{P}=$ $0.021)$. Compared with patients who received dexamethasone alone, patients who received dexamethasone + mannitol had significantly higher RR (56.4\% vs. $35.9 \%, \mathrm{P}=0.038)$.

\section{NIHSS score}

Before the treatment, the average NIHSS scores between the experimental and the control groups were similar (experimental group: $17.48 \pm 0.29$ vs. control group: $17.26 \pm 0.24, \mathrm{P}=0.902$ ). After the treatment, the average NIHSS scores of the experimental and control groups were significantly decreased (experimental group: after $11.25 \pm 0.36$ vs. before treatment $17.48 \pm 0.29$, $\mathrm{P}<0.001$; control group: after $14.62 \pm 0.30$ vs. before treatment $17.26 \pm 0.24, \mathrm{P}=0.001$ ). The ANCOVA results showed that the NIHSS score of the experimental group was significantly lower than that of the control group (experimental group: $11.25 \pm 0.36$ vs. control group: $14.62 \pm 0.30, \mathrm{P}$ $=0.028$ ). Furthermore, compared with patients who received dexamethasone alone, patients who received dexamethasone + mannitol had a significantly lower average NIHSS scores (E2 group: $11.28 \pm 0.28$ vs. E1 group: $13.97 \pm 0.33$, $\mathrm{P}=0.022$ ) (Figures 1 and 2).

\section{MBP level}

Before the treatment, no significant difference was observed in the MBP levels between the experimental and control groups (experimental group: $12.40 \pm 0.31$ vs. control group: $12.36 \pm$ $0.22, \mathrm{P}=0.585)$. After the treatment, MBP levels in the experimental and control groups were significantly decreased (experimental group: after $4.90 \pm 0.76$ vs. before treatment $12.40 \pm 0.31$, $\mathrm{P}=0.010$; control group: after $7.62 \pm 0.37$ vs. before treatment $12.36 \pm 0.22, \mathrm{P}=0.004)$. The ANCOVA results showed that the MBP level in the experimental group was significantly lower than that in the control group (experimental group: $4.90 \pm 0.76$ vs. control group: $7.62 \pm 0.37, \mathrm{P}=$ 0.019). Furthermore, compared with patients who received dexamethasone alone, patients who received dexamethasone + mannitol had a significantly lower level of MBP (E2 group: $3.75 \pm 0.78$ vs. $\mathrm{E} 1$ group: $7.23 \pm 0.63, \mathrm{P}=0.002$ ) (Figure 3).

Table 2: RR in the two groups at baseline and end of the fourth week based on MMSE scores

\begin{tabular}{lccccccc}
\hline Time & Group & n & $\mathbf{0 - 9}$ & $\mathbf{0 - 2 4}$ & $\mathbf{2 5 - 3 0}$ & RR & P-value \\
\hline Baseline & Control & 156 & 114 & 42 & 0 & - & - \\
& E1 & 78 & 57 & 21 & 0 & - & - \\
\multirow{5}{*}{ Fourth week } & E2 & 78 & 59 & 19 & 0 & - & - \\
& Control & 156 & 100 & 18 & 38 & $24.4 \%$ & $0.021^{\mathrm{a}}$ \\
& E1 & 78 & 30 & 20 & 28 & $35.9 \%$ & $0.038^{\mathrm{b}}$ \\
& E2 & 78 & 4 & 30 & 44 & $56.4 \%$ & \\
\hline
\end{tabular}

Notes: a) P-value of the control vs. experimental group on RR; b) P-value of E1 vs. E2 on RR; E1, patients who received $10 \mathrm{mg}$ /day dexamethasone $+125 \mathrm{ml}$ per $12 \mathrm{~h}$ mannitol; E2, patients who received $10 \mathrm{mg} /$ day dexamethasone. Abbreviations: MMSE, Mini-Mental State Examination; RR, remission rate. 

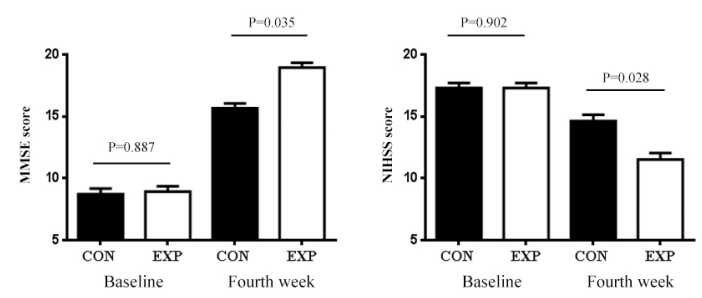

Figure 1. MMSE and NIHSS scores in the experimental and control groups.
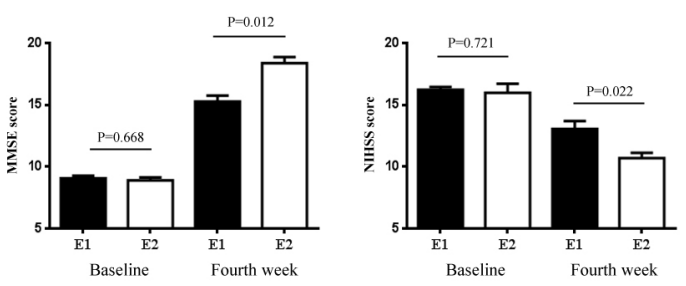

Figure 2. MMSE and NIHSS scores in E1 (10 mg/ day dexamethasone) and E2 (100 ml per 12 $\mathrm{h}$ mannitol and $10 \mathrm{mg} /$ day dexamethasone) groups.
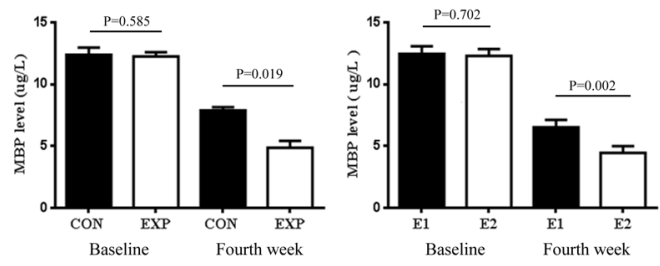

Figure 3. Level of MBP in CSF of patients with DNS.

\section{Adverse events}

During the whole course of treatment, no serious adverse events were observed in the two groups. No significant increase in blood glucose or renal impairment was observed. In the experimental group, 1 case of mild nausea, 1 case of bloating, 1 case of phlebitis and 1 case of dizziness were noted. In the control group, 1 patient had mild nausea, 3 patients had mild headache, and 2 patients had loss of appetite. All patients with adverse events recovered by themselves and did not require special treatment.

\section{DISCUSSION}

Since the use of $\mathrm{HBO} 2$ in the treatment of $\mathrm{CO}$ poisoning in 1960, the effects, timing and sessions of HBO2 therapy have been controversial due to methodological limitations. Six prospective clinical trials have compared the clinical efficacy of $\mathrm{HBO} 2$ and $\mathrm{NBO}$ in the treatment of acute $\mathrm{CO}$ poisoning, four of which have found better clinical outcomes for $\mathrm{HBO} 2$, whereas two have no positive effect. To date, most experts in the field have advocated that $\mathrm{HBO} 2$ can be used to treat severe $\mathrm{CO}$ poisoning to limit delayed and permanent neurological sequelae. ${ }^{15,16,22,28-32}$ Once DNS occurs, symptomatic and supportive treatments are often used. ${ }^{33} \mathrm{HBO} 2$ is widely used in China to treat DNS on the basis that it increases blood oxygen content in brain tissues, exerts anti-inflammatory and antioxidant effects, and promotes stem cell differentiation and proliferation and recovery of damaged nerve cells. ${ }^{34}$

Hypoxic-ischemic, excitotoxicity, acidosis, ion imbalance and depolarisation, oxidative stress, nitrification stress, inflammation, apoptosis and oligodendrocyte regeneration failure may be involved in $\mathrm{CO}$ poisoning-induced brain damage and DNS. However, none of the above mechanisms can fully explain its pathogenesis. ${ }^{6-11,35}$ Increasing evidence suggests that delayed neuropathology after $\mathrm{CO}$ poisoning is immune-mediated. ${ }^{9} \mathrm{CO}$ poisoning can activate platelets by replacing nitric oxide from platelet blood proteins. Free nitric oxide reacts with superoxide to form peroxynitrite, which further increases platelet activation. Activated platelets can stimulate neutrophil degranulation and release myeloperoxidase (MPO), thereby activating neutrophil activation, adhesion and degranulation, further enhancing immune inflammatory effects. Proteases in neutrophils can oxidise endothelial xanthine dehydrogenase to xanthine oxidase to produce reactive oxygen species (ROS). MPO and ROS catalyse lipid metabolism, and oxidation forms an adduct with MBP (the main component of the central nervous system, accounting for approximately $30 \%$ of myelin proteins), activating lymphocyte responses and microglial activation, inducing autoimmune cascades and further degrading MBP in the brain. When MBP is degraded and released into the CSF and blood, it can further cause an autoimmune response, attack the normal brain MBP and induce progressive demyelination, leading to DNS. ${ }^{9,36-39}$ MBP in CSF can be used as a predictor of DNS..$^{27,40-42}$ Therefore, blocking the immune inflammatory response may be an effective means to prevent the occurrence and development of DNS. Glucocorticoids have powerful anti-immune effects. Li et al. found that dexamethasone may reduce the inflammatory response by protecting the myelin sheath from the inflammatory response and also reduce the oedema and permeability of hypoxic-ischaemic brain tissue and neuronal damage. ${ }^{43}$ Atalay et al. reported that dexamethasone may treat $\mathrm{CO}$ 
poisoning rats by intervening in brain tissue lipid peroxidation. ${ }^{44}$ Xiang et al. conducted a series of studies on the role and mechanism of dexamethasone in DNS treatment at the animal and clinical levels. They found that dexamethasone treatment could inhibit neutrophil activation and inflammatory response-mediated nerve damage by inhibiting MPO expression and significantly reduced the escape latency of rats and MBP expression levels in serum and hippocampus. In addition, they recruited 120 patients with DNS to evaluate the neurocognitive function, RR and MBP expression in the CSF of dexamethasone combined with $\mathrm{HBO} 2$ therapy. They found that after 4 weeks of treatment, the experimental group had a significantly higher RR and average MMSE score and a significantly lower average NIHSS score compared with the control group. Meanwhile, a trend toward better improvement with dexamethasone $10 \mathrm{mg} /$ day was observed, and the MBP level in the CSF of patients was significantly lower in the experimental group than in the control group. The addition of dexamethasone did not significantly increase the incidence of adverse events. ${ }^{23,45}$ Based on our experience in the clinical treatment of DNS in recent years and Xiang et al.'s study, we designed this study and found that $\mathrm{HBO} 2$ therapy as monotherapy and the combined application of 10 $\mathrm{mg}$ /day dexamethasone and $\mathrm{HBO} 2$ therapy could significantly improve the MMSE score and reduce the NIHSS score and MBP level. In addition, the RR is high in patients with DNS. These results indicate that the combined application of dexamethasone and $\mathrm{HBO} 2$ therapy could indeed yield better efficacy for patients with DNS and should be regarded as a potential new therapy.

DWI can objectively and quantitatively indicate the degree of diffusion of water molecules in tissues. It is more sensitive than conventional MRI and can demonstrate cytotoxic oedema in damaged WM earlier. Cytotoxic oedema in acute ischemic lesions is characterised as high signal on DWI and low ADC value. ${ }^{46}$ DWI examination in patients with acute or subacute stage of $\mathrm{CO}$ poisoning showed decreased ADC values and increased DWI signals at bilateral frontal and parietal WM at 12 and $48 \mathrm{~h}$ after CO poisoning. ${ }^{47,48}$ DWI studies on the subacute and chronic phases of $\mathrm{CO}$ poisoning found that the WM areas with high DWI signals and low ADC value during the acute phase persisted in the subacute and chronic phases..$^{49}$ Patients with DNS can have high DWI signals and low ADC values for 1-2 months. ${ }^{24,50}$ Therefore, the DWI performance of patients with $\mathrm{CO}$ poisoning and cerebral infarction is different (ADC values are low at 3-5 days and return to normal within 1-4 weeks after stroke). This result suggests that WM damage in patients with $\mathrm{CO}$ poisoning cannot be simply explained by local ischaemia, but patients with DNS may develop progressive demyelination with cytotoxic oedema. Drugs currently available for controlling oedema include mannitol, hypertonic saline and corticosteroids. Amongst them, mannitol has the longest clinical application and the widest range. As a hypertonic drug, the main mechanisms of mannitol dehydration are osmosis and haemodynamics. Mannitol does not cross the cell membrane or the intact blood-brain barrier; thus, it increases intravascular tension, thereby establishing a concentration gradient across the blood-brain barrier, forcing water to move from the oedema brain tissue into the blood vessels. The haemodynamic effects of mannitol are thought to be mediated by a decrease in blood viscosity, which results in an increase in cerebral blood flow and a subsequent decrease in cerebral blood volume due to passive vasoconstriction. ${ }^{51}$ Although mannitol has a poor effect on cellular oedema, it also has the effects of scavenging free radicals, inhibiting apoptosis and regulating cerebral perfusion pressure (increasing cerebral perfusion pressure leading to self-regulating vasoconstriction and subsequent reduction of cerebral blood volume). ${ }^{52} \mathrm{We}$ found that compared with the $\mathrm{HBO} 2$ alone and $\mathrm{HBO} 2$ combination with dexamethasone groups, the ' $10 \mathrm{mg} /$ day dexamethasone + $100 \mathrm{ml} / 12 \mathrm{~h}$ mannitol + HBO2' combination therapy for patients with DNS could further improve the MMSE score and RR, reduce the NIHSS score and MBP levels and did not significantly increase the incidence of adverse events. Therefore, these results indicate that the combined application of 'dexamethasone + mannitol + HBO2' may be a potentially effective treatment for patients with complications of DNS.

In conclusion, our study found that 'dexamethasone + mannitol + $\mathrm{HBO} 2$ ' combination therapy is better than $\mathrm{HBO} 2$ as a monotherapy and dexamethasone $+\mathrm{HBO} 2$ therapy in patients with DNS. It is a potentially effective strategy for the prevention and treatment of DNS. However, some limitations exist in our study. 1) We did not conduct the sample size calculation. 2) We only assessed the efficacy of dexamethasone, mannitol and $\mathrm{HBO} 2$ therapy in the acute phase treatment of DNS. Thus, future studies are needed to assess its long-term efficacy. 3) We only randomised the patients into two groups 
(control and experimental) and then splitting the experimental group because our study followed the study by Xiang et al. ${ }^{23}$ It would have been better to randomise the recruited patients into three groups (control, E1 and E2) right from the start. Thus, a large sample, multi-centre, randomised controlled study is needed to further validate our findings.

\section{ACKNOWLEDGEMENTS}

Sincere gratitude is extended to the nurses in our department and participants for their efforts and cooperation.

\section{DISCLOSURE}

Financial support: This study was funded by the Natural Science Foundation of China (81401063), Beijng Nova Program (Z161100004916144), The Natural Science Foundation of Beijing (7153175) and Capital Public Health project Z141100002114039.

\section{Conflicts of interest: None}

\section{REFERENCES}

1. Hampson NB. U.S. mortality due to carbon monoxide poisoning, 1999- 2014. Accidental and intentional deaths. Ann Am Thorac Soc 2016; 13(10): 1768-74.

2. Rose JJ, Wang L, Xu Q, et al. Carbon monoxide poisoning: Pathogenesis, management, and future directions of therapy. Am J Respir Crit Care Med 2017; 195(5): 596-606.

3. Bleecker ML. Carbon monoxide intoxication. Handb Clin Neurol 2015; 131:191-203.

4. Hsiao CL, Kuo HC, Huang CC. Delayed neurological sequelae after carbon monoxide intoxication long-term prognosis and correlation of clinical manifestations and neuroimages. Acta Neurol Taiwan 2004; 13: 64-70.

5. Hampson NB, Piantadosi CA, Thom SR, Weaver LK. Practice recommendations in the diagnosis, management, and prevention of carbon monoxide poisoning. Am J Respir Crit Care Med 2012; 186(11): 1095-101.

6. Garrabou G, Inoriza JM, Morén C, et al.Mitochondrial injury in human acute carbon monoxide poisoning: the effect of oxygen treatment. J Environ Sci Health C Environ Carcinog Ecotoxicol Rev 2011; 29(1): 32-51.

7. Bauer I, Pannen BH. Bench-to-bedside review: Carbon monoxide from mitochondrial poisoning to therapeutic use. Crit Care 2009; 13(4): 220.

8. Thom SR, Bhopale VM, Han ST, Clark JM, Hardy KR. Intravascular neutrophil activation due to carbon monoxide poisoning. Am J Respir Crit Care Med 2006; 174(11): 1239-48.

9. Thom SR, Bhopale VM, Fisher D, Zhang J, Gimotty
P. Delayed neuropathology after carbon monoxide poisoning is immune-mediated. Proc Natl Acad Sci USA 2004; 101: 13660-5.

10. Hara S, Mizukami H, Kurosaki K, Kuriiwa F, Mukai T. Existence of a threshold for hydroxyl radical generation independent of hypoxia in rat striatum during carbon monoxide poisoning. Arch Toxicol 2011; 85(9): 1091-9.

11. Guo D, Hu H, Pan S. Oligodendrocyte dysfunction and regeneration failure: A novel hypothesis of delayed neurological sequelae after carbon monoxide poisoning. Med Hypotheses 2019; 136:109522.

12. Huang H, Sharma HS, Chen L, Saberi H, Mao G. 2018 yearbook of neurorestoratology. J Neurorestoratology 2019, 7(1): 11-20.

13. Huang H, Chen L, Mao G, et al. The 2019 yearbook of neurorestoratology. J Neurorestoratology 2020; 8(1): 1-11.

14. Yang Y, Xu L, Xie R, et al. A meta-analysis on the efficiency of the time window of hyperbaric oxygen treatment on disorders of consciousness in China. $J$ Neurorestoratology 2020, 8(4): 270-80.

15. Weaver LK, Hopkins RO, Chan KJ, et al. Hyperbaric oxygen for acute carbon monoxide poisoning. $N$ Engl J Med 2002; 347: 1057-67.

16. Raphael JC, Elkharrat D, Jars-Guincestre MC, et al. Trial of normobaric and hyperbaric oxygen for acute carbon monoxide intoxication. Lancet 1989;2: 414-19.

17. Thom SR, Taber RL, Mendiguren II, Clark JM, Hardy $\mathrm{KR}$, Fisher AB. Delayed neuropsychologic sequelae after carbon monoxide poisoning: prevention by treatment with hyperbaric oxygen. Ann Emerg Med 1995; 25:474-80.

18. Mathieu D, Wattel F, Mathieu-Nolf M, et al. Randomized prospective study comparing the effect of $\mathrm{HBO} 2$ vs. 12 hours NBO in non-comatose COpoisoned patients: results of the preliminary analysis. Undersea Hyperb Med 1996; 23:7..

19. Scheinkestel CD, Bailey M, Myles PS, et al. Hyperbaric or normobaric oxygen for acute carbon monoxide poisoning: a randomised controlled clinical trial. Med J Aust 1999; 170:203-10.

20. Raphael JC, Chevret S, Driheme A, Annane D. Managing carbon monoxide poisoning with hyperbaric oxygen. J Toxicol Clin Toxicol 2004; 42:455-6.

21. Annane D, Chadda K, Gajdos P, Jars-Guincestre MC, Chevret S, Raphael JC. Hyperbaric oxygen therapy for acute domestic carbon monoxide poisoning: two randomized controlled trials. Intensive Care Med 2011;37: 486-92.

22. Ducasse' JL, Celsis P, Marc-Vergnes JP. Noncomatose patients with acute carbon monoxide poisoning: hyperbaric or normobaric oxygenation? Undersea Hyperb Med 1995; 22:9-15.

23. Xiang W, Xue H, Wang B, et al. Combined application of dexamethasone and hyperbaric oxygen therapy yields better efficacy for patients with delayed neurological sequelae after acute carbon monoxide poisoning. Drug Des Devel Ther 2017; 11:513-9.

24. Kim JH, Chang KH, Song IC, et al. Delayed neurological sequelae of acute carbon monoxide 
intoxication: diffusivity of cerebral white matter lesions. AJNR Am J Neuroradiol 2003; 24(8): 1592-7.

25. Okubo T, Aoki $\mathrm{S}$, Abe $\mathrm{O}$, et al. Principles of diffusionweighted MR imaging and application to clinical neurology. Rinsho Shinkeigaku 2004; 44(11): 954-6.

26. Kim DM, Lee IH, Park JY, Hwang SB, Yoo DS, Song CJ. Acute carbon monoxide poisoning: MR imaging findings with clinical correlation. Diagn Interv Imaging 2017; 98(4): 299-306.

27. Kuroda H, Fujihara K, Mugikura S, Takahashi S, Kushimoto S, Aoki M. Altered white matter metabolism in delayed neurologic sequelae after carbon monoxide poisoning: A proton magnetic resonance spectroscopic study. J Neurol Sci 2016; 360:161-9.

28. Thom SR, Taber RL, Mediguren II, Clark JM, Hardy KR, Fisher AB. Delayed neuropsychologic sequelae after carbon monoxide poisoning: prevention with hyperbaric oxygen. Ann Emerg Med 1995; 25: 47480.

29. Mathieu D, Wattel F, Mathieu-Nolf M, Tempe JF, Bouachour G, Sainty JM. Randomized prospective study comparing the effect of $\mathrm{HBO} 22$ versus 12 hours of NBO in non comatose $\mathrm{CO}$ poisoned patients: results of the interim analysis. Undersea Hyperb Med 1996; 23:7-8.

30. Scheinkestel CD, Bailey M, Myles PS, et al. Trial of normobaric and hyperbaric oxygen for acute carbon monoxide poisoning: a randomized controlled clinical trial. Med J Aust 1999;170: 203-10.

31. Annane D, Chadda K, Gajdos P, Jars-Guincestre MC, Chevret S, Raphael JC. Hyperbaric oxygen for acute domestic carbon monoxide poisoning: two randomized controlled trials. Intensive Care Med 2011;37: 486-92.

32. Weaver LK, Valentine KJ, Hopkins RO. Carbon monoxide poisoning: risk factors for cognitive sequelae and the role of hyperbaric oxygen. Am J Respir Crit Care Med 2007; 176:491-7.

33. Yanagiha K, Ishii K, Tamaoka A. Acetylcholinesterase inhibitor treatment alleviated cognitive impairment caused by delayedencephalopathy due to carbon monoxide poisoning: Two case reports and a review of the literature. Medicine (Baltimore) 2017; 96(8): e6125.

34. Hadanny A, Suzin G, Lang E, Efrati S. Hyperbaric oxygen therapy- Basics and new applications. Harefuah 2018: 157(5): 322-6.

35. Kara H, Bayir A,AkA, Degirmenci S.Cerebrovascular ischaemia after carbon monoxide intoxication. Singapore Med J 2015; 56(2): e26-28.

36. Thom SR, Ohnishi ST, Ischiropoulos H. Nitric oxide released by platelets inhibits neutrophil B2 integrin function following acute carbon monoxide poisoning. Toxicol Appl Pharmacol 1994; 128:105-10.

37. Thom SR, Fisher D, Manevich Y. Roles for plateletactivating factor and $* \mathrm{NO}$-derived oxidants causing neutrophil adherence after $\mathrm{CO}$ poisoning. $A m J$ Physiol Heart Circ Physiol 2001; 281(2): H923-30.

38. Yang L, Tan D, Piao H. Myelin basic protein citrullination in multiple sclerosis: A potential therapeutic target for the pathology. Neurochem Res 2016; 41(8): 1845-56.
39. Thom SR, Xu YA, Ischiropoulos H. Vascular endothelial cells generate peroxynitrite in response to carbon monoxide exposure. Chem Res Toxicol 1997; 10: 1023-31.

40. Thom S. Carbon monoxide pathophysiology and treatment. In: Neuman T, Thom, SR, eds: Physiology and medicine of hyperbaric oxygen therapy. Philadelphia: Saunders Elsevier; 2008. 321-47.

41. Kamijo Y, Soma K, Ide T. Recurrent myelin basic protein elevation in cerebrospinal fluid as a predictive marker of delayed neurological sequelae after carbon monoxide poisoning. Am J Emerg Med 2007; 25(4): 483-5.

42. Ide T, Kamijo Y. Myelin basic protein in cerebrospinal fluid: a predictive marker of delayed neurological sequelae from carbon monoxide poisoning. Am J Emerg Med 2008; 26(8): 908-12.

43. Li Q, Song JJ, Zhang HY, Fu K, Lan HB, Deng Y. Dexamethasone therapy for preventing delayed neurological sequelae after carbon monoxide poisoning. Biotech Histochem 2015; 90(8): 561-7.

44. Atalay H, Aybek H, Koseoglu M, et al. The effects of amifostine and dexamethasone on brain tissue lipid peroxidation during oxygen treatment of carbon monoxide-poisoned rats. Adv Ther 2006; 23(2):332-41.

45. Xiang WP, Xue H, Wang BJ. Delayed neurological sequelae of acute carbon monoxide intoxication in rats: potential mechanismand intervention of dexamethasone. Pak J Pharm Sci 2014; 27(6 Suppl): 2025-8.

46. Teksam M, Casey SO, Michel E, et al. Diffusionweighted MR imaging findings in carbon monoxide poisoning. Neuroradiology 2002; 44:109-13.

47. Sener RN. Acute carbon monoxide poisoning: diffusion MR imag- ing findings. AJNR Am J Neuroradiol 2003; 24:1475-7.

48. Schönfeld MH, Ritzel RM, Kemmling A, Ernst M, Fiehler J, Gellißen S. Improved detectability of acute and subacute brainstem infarctions by combining standard axial and thin-sliced sagittal DWI. PLoS One 2018; 13(7): e0200092.

49. Kinoshita T, Sugihara S, Matsusue E, et al. Pallidoreticular damage in acute carbon monoxide poisoning: diffusion-weighted MR imaging findings. AJNR Am J Neuroradiol 2005; 26:1845-8.

50. Rosner MJ, Coley I. Cerebral perfusion pressure: a hemodynamic mechanism of mannitol and the postmannitol hemogram. Neurosurgery1987; 21: 147-56.

51. Alvarez B, Ferrer-Sueta G, Radi R. Slowing of peroxynitrite decomposition in the presence of mannitol and ethanol. Free Radic Biol Med 1998; 24: 1331-7.

52. Deng YY, Shen FC, Xie D, et al. Progress in drug treatment of cerebral edema. Mini Rev Med Chem 2016; 16(11): 917-25. 